\title{
Research Paper: Evaluating Muscle Activity During Work With Trackball, Trackpad, Slanted, and Standard Mice
}

\author{
Yasser Labbafinejadi $^{1}$ (D), Mansour Eslami-Farsani ${ }^{1}$ (D), Saber Mohammadi' ${ }^{\text {(D), Mohamad Sadegh Ghasemi }}{ }^{2}$ (D), Mahnoush Reiszadeh${ }^{1}$ (D), \\ Naser Dehghan $^{3^{*}}$ (D)
}

1. Department of Occupational Medicine, School of Medicine, Iran University of Medical Sciences, Tehran, Iran.

2. Department of Ergonomics, School of Health, Iran University of Medical Sciences, Tehran, Iran.

3. Occupational Medicine Research Center, Iran University of Medical Sciences, Tehran, Iran.

\begin{tabular}{|c|c|}
\hline $\begin{array}{l}\text { Use your device to scan } \\
\text { and read the article online }\end{array}$ & Chat on Labbafineiad Y Eslami-Farsani M. Mohammadi S, Ghasemi MS, Reiszadeh M. Dehohan N. Evaluating Muscle Activ- \\
\hline 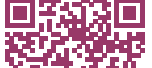 & $\begin{array}{l}\text { ity During Work With Trackball, Trackpad, Slanted, and Standard Mice. Iranian Rehabilitation Journal. 2019; 17(2):121-128. http:// } \\
\text { dx.doi.org/10.32598/irj.17.2.121 }\end{array}$ \\
\hline arstipt & dol' http://dx.doi.org/10.32598/irj.17.2.121 \\
\hline
\end{tabular}

\section{(i) (3)}

Article info:

Received: 01 Oct 2018

Accepted: 28 Jan 2019

Available Online: 01 June 2019

Keywords:

Electromyography,

Ergonomics, Computer mouse, Input devices

\section{ABSTRACT}

Objectives: Mouse is one of the most important data entry devices for computers. Undesirable and prolonged postures during work with the computer mouse increase workload, muscle aches and upper extremity musculoskeletal disorders. The present study aimed to evaluate and compare muscle activity during the use of 4 types of mouse, including trackball, trackpad, slanted and standard by Electromyography (EMG).

Methods: This experimental study included 15 subjects ( 7 men and 8 women). The electrical activity of EDC, ECU, ECR, FDS, PQ, and FDL muscles was recorded by EMG while performing a standard task with each mouse. The order of using each mouse was randomized. The obtained results were analyzed by SPSS using the measures of central tendency, Friedman's test, and Independent Samples t-test.

Results: The results of assessing the electrical activity level of muscles suggested no statistically significant difference in the recorded EMG between FPL, FDS, and PQ muscles while working with the 4 mice. The electrical activity reduced in EDC, ECR, and FPL muscles with the use of slanted mouse, compared to that of other mice $(\mathrm{P}<0.05)$.

Discussion: There was no significant differences between the electrical activity of FDS, FPL, and PQ muscles during work with the studied mice. Furthermore, the activity of EDC, ECR, and FPL muscles reduced during work with a slanted mouse, compared to the other types. The habit of using a new mouse can affect the level of muscle activity; thus, the use of a slanted mouse may reduce the incidence of musculoskeletal disorders in the wrist and hand of users in the long run.

\section{* Corresponding Author:}




\section{Highlights}

- The slanted mouse (slant angle $=30^{\circ}$ or $50^{\circ}$ ) may lead the future market in computer accessories and replace conventional mouse (slant angle $=0^{\circ}$ ).

- A slanted mouse may reduce the incidence of musculoskeletal disorders in users' wrists and hands in the long run.

\section{Plain Language Summary}

A slanted mouse (slant angle $=30^{\circ}$ and $50^{\circ}$ ) is superior to an ordinary mouse based on EMG results. Furthermore, the electrical activity of the hand muscles reduces when working with the slanted mouse. The slanted mouse may lead the computer accessories market and replace the conventional mouse. Further practice of the users with the new ergonomic mouse may improve its functional parameters. Besides, the electrical activity of muscles decreases when working with this new mouse design. In the long term, it can reduce the incidence of musculoskeletal disorders in users' wrists and hands.

\section{Introduction}

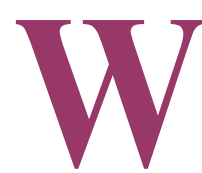

ork-related musculoskeletal disorders are the most important problems in the health of workforce. These discomforts cause many working days lost, increase absenteeism from work, and impose annual economic costs $[1,2]$. Electromyography (EMG) is a common method for investigating the relationship between an optimal mouse design and the risk of musculoskeletal disorders. This device measures action potentials produced by the muscles [3]. Most studies evaluating different mouse types have used EMG. This is because of its favorable predictive nature of the wrist position, posture, pressure on the body, and movements [4].

In these experiments, the standard task is repeated by the participants by considering some variables where a common variable is used for this purpose. EMG can measure the diagrams generated from the electrical activity of each individual muscle in the same task by different mice. When evaluating the mice, it is necessary to examine the electrical activity of the most involved muscles. Agarabi et al. evaluated the ECU, ED, PQ, FDS, FDI and SDI muscles [4].

Lee et al. examined the ECU, FDS, FDI, EDC, and ECR muscles [5]. Dennerlein et al. studied the ECU, ECR, FCU, FCR, anterior deltoid, and middle deltoid muscles, and the upper trapezius [6]. Hengel et al. examined the ECU, ED, FDI, and ECR muscles [7]. The ECR and ECU muscles in the wrist and the ED muscle in the fingers have most been evaluated while working with a mouse [8]. These muscles are at higher risk of musculoskeletal disorders when working with a mouse [5].
EMG signals are highly variable which can be due to the random nature of action potentials and functional differences in individuals. These differences are more frequent in comparing different people. The amount of fat or muscle in the hands causes changes in the physical activity curve of individuals. In addition, the difference in the forearm structure may also affect it.

To improve these differences, many studies have used Maximum Voluntary Contraction (MVC). Most of these studies have applied EMG to measure the wrist muscle strength in isometric tasks [9]. The EMG test is highly affected by noise. The common noise sources include electrodes and cable movements, potential electrode aggregation, and electromagnetic interference caused by alternating current [4]. To reduce the noise, dead skin cells must be removed, which reduces electrical resistance between the skin and the electrode. Many studies have recommended cotton and alcohol for cleaning the skin [10].

Considering the importance of the aforementioned literature, further research is required on the electrical activity of muscles while working with a computer mouse [3-5]. Therefore, the present study evaluated the performance and convenience of 4 different computer mice, using EMG.

\section{Methods}

\section{The study participants}

The present experimental study was conducted on 15 software design engineers, including 7 men and 8 women. All participants were right-handed. A standard task was designed and they were requested to complete it with each mouse for 5 minutes. The study participants 
aged 25 to 45 years. Prior to conducting the test, each study participant was requested to perform a standard task with each mouse for several times to reduce the effect of habit on the test.

\section{Input devices}

At this stage, 4 different mouse types, including trackball, trackpad, slanted and standard were examined (Figure 1). To eliminate the effect of habit on the desired task, the order of presenting the mice to each subject was randomly determined; this also prevented the effect of order and carryover effect.

\section{The standard task}

This task included clicking on 20 squares that were arranged in numbers in two rows of 10 . For each mouse, this task was performed by each subject for 5 minutes to record EMG data [11].

The study muscles

This study examined 6 muscles, including Extensor Digitorum Communis (EDC), Extensor Carpi Ulnaris (ECU), Extensor Carpi Radialis (ECR), Flexor Digitorum Superficialis (FDS), Pronator Quadrates (PQ), and Flexor Pollicis Longus (FPL).
These muscles play a major role while working with a mouse [5]. At first, the mean activity level of each muscle was calculated; then, the electrical activity of each muscle was obtained as a percentage of the MVC. The quantitative data obtained from electrical activity was expressed as the percentage of MVC for each muscle. The use of each mouse was separately recorded for each sample and averaged in 15 samples. To control the confounding factors of the effect of habit on the desired task, the order of using the 4 mice was randomly considered for each participant. The electrical activity of muscles was recorded using the portable EMG (DataLOG, MWX8) and the related computer software (Biometrics Ltd ${ }^{\circledR}$, the UK) (Figure 2).

During the evaluation, a five-minute rest was given in the interval of each task with each mouse, to prevent the effect of fatigue. The conditions of the laboratory environment were the same for all participants. Each participant was requested to set their seat height to feel comfortable in a natural posture.

\section{Data extraction and data processing}

The EMG recordings were converted into quantitative data by Biometrics Analysis Software. SPSS was used to analyze and compare the data. The Friedman two-way Analysis of Variance (ANOVA) was used to compare the

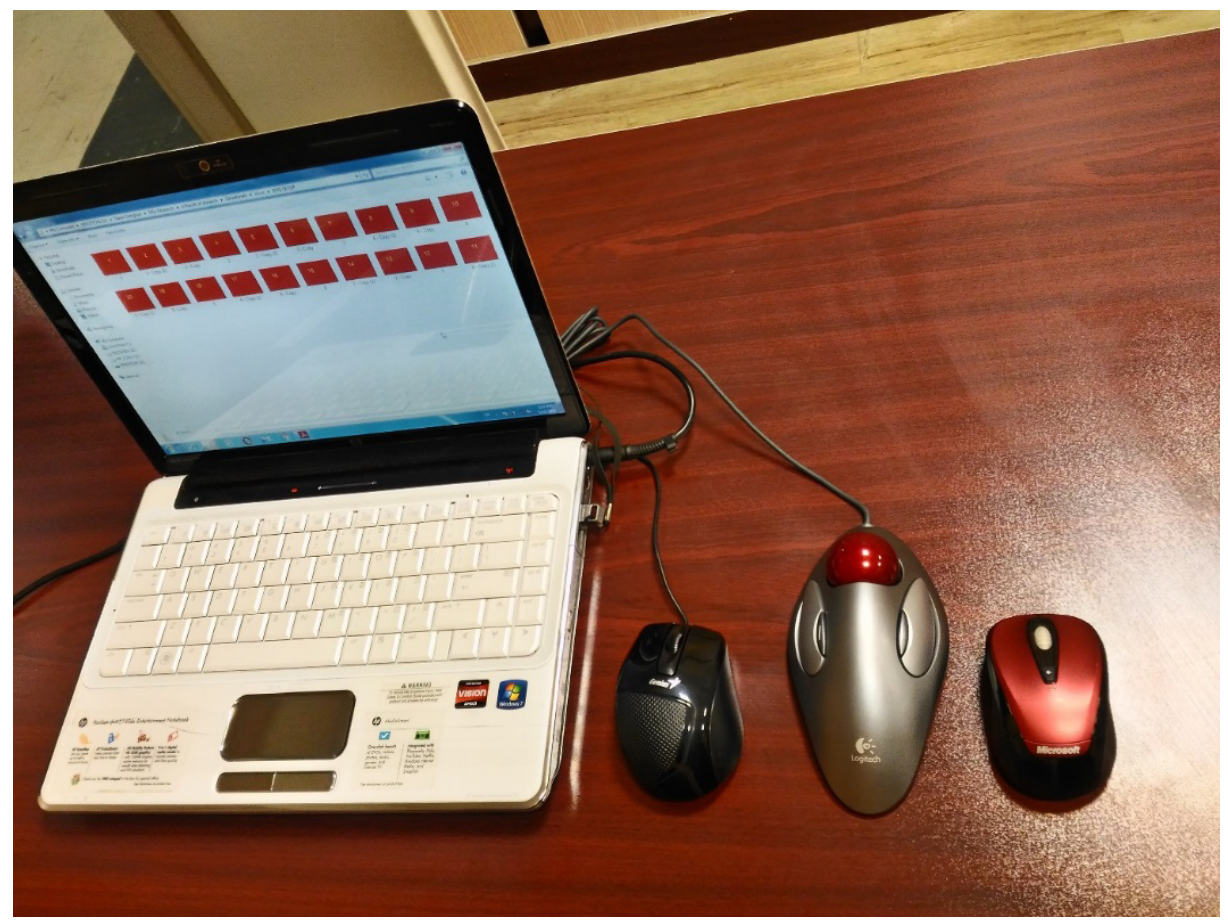

Figure 1. Input devices

Iranian Rehabilitation Journal

Left to right: trackpad, slanted mouse, trackball mouse, and standard mouse 


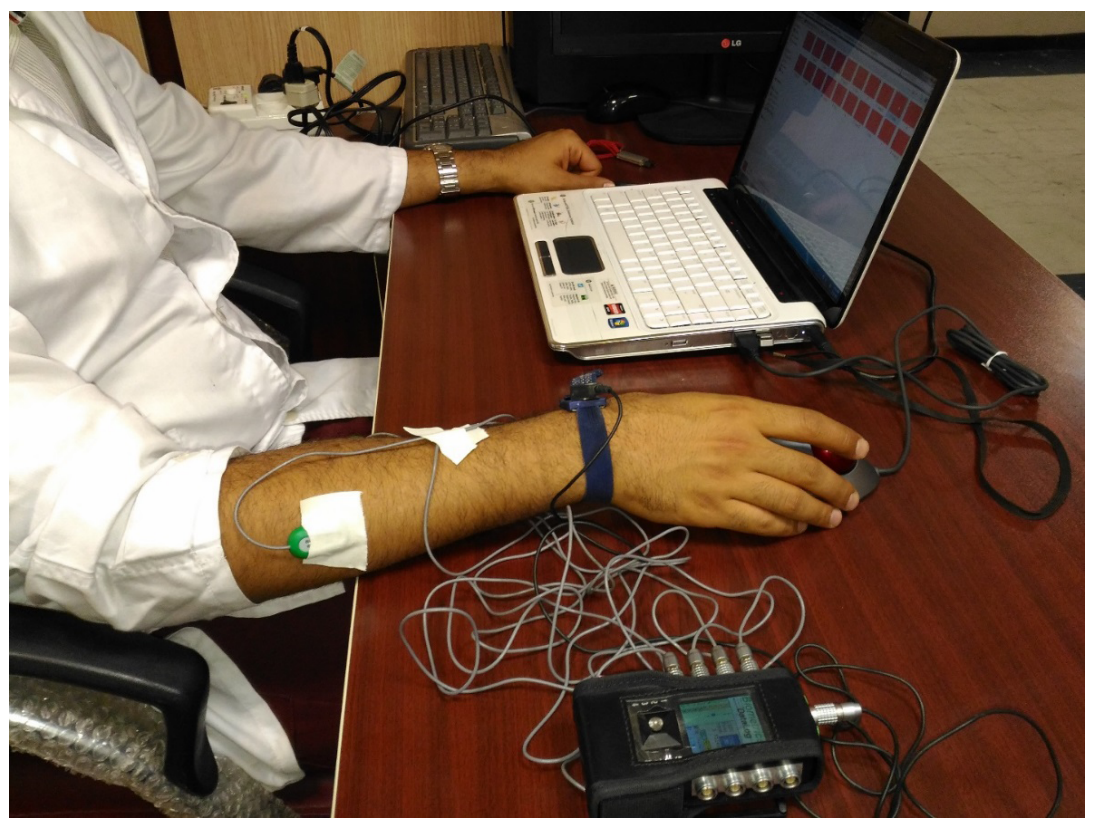

Figure 2. EMG of the user during the task with a trackball mouse

Iranian Rehabilitation Journal

electrical activity levels of the muscles when working with each mouse.

\section{Results}

The Mean \pm SD age and work experience with the computer of 15 participants were $28.4 \pm 4.61$ and $11.2 \pm 2.1$ years, respectively. Table 1 presents the demographic characteristics of the study participants. As per Table 2, the mean activity level of EDC, ECR, and FPL muscles for the slanted mouse were 11.02, 7.41, and 14.93, respectively; these were the lowest values, compared with the other mouse types. The activity level of ECU muscle during work with the standard mouse was the lowest (12.93). The lowest levels of activity for FDS and PQ muscles during work with trackball mouse were obtained as 3.52 and 3.36, respectively.
The electrical activity of muscles during operation with a slanted mouse in EDC, ECR, FDS, FPL, and PQ muscles was less than that of a standard mouse. According to the above table, the Friedman two-way ANOVA results revealed no significant differences in the EMG activity level between FPL, FDS, and PQ muscles when using the 4 mice. However, there was a significant difference between the obtained results for EDC, ECU, and ECR muscles.

\section{Discussion}

The Friedman two-way ANOVA results indicated no significant differences in the EMG assessments of FDS, FPL, and PQ muscles in respect of the 4 studied mice. This suggests that the studied mice are approximately similar in terms of the activity of these three muscles during usage. Therefore, the differences in the design of the studied mice had no effect on the electrical activity of these muscles. According to previous studies, these are the 3 main mus-

Table 1. The demographic characteristics of the study participants $(n=15)$

\begin{tabular}{cc}
\hline Variable & Mean \pm SD \\
\hline Age, $y$ & $28.4 \pm 4.61$ \\
\hline Height, $\mathrm{cm}$ & $171.24 \pm 7.12$ \\
\hline Weight, $\mathrm{kg}$ & $70.23 \pm 10.13$ \\
\hline Work experience with the computer, $\mathrm{y}$ & $11.2 \pm 2.11$ \\
\hline Daily working hours with the computer, $\mathrm{h}$ & $5.42 \pm 1.26$ \\
\hline
\end{tabular}


Table 2. Mean \pm SD scores of muscle electrical activity as a percentage of MVC during work with the 4 types of mouse $(n=15)$

\begin{tabular}{|c|c|c|c|c|c|}
\hline \multirow{2}{*}{ Muscle } & \multicolumn{4}{|c|}{ Mean士SD } & \multirow{2}{*}{ P* } \\
\hline & Trackball Mouse & Trackpad Mouse & Slanted Mouse & Standard Mouse & \\
\hline EDC & $13.38 \pm 4.49$ & $15.08 \pm 5.25$ & $11.02 \pm 2.12$ & $11.98 \pm 4.21$ & 0.03 \\
\hline ECU & $19.87 \pm 5.68$ & $14.32 \pm 4.43$ & $14.92 \pm 5.98$ & $12.94 \pm 3.83$ & 0.01 \\
\hline ECR & $9.31 \pm 3.28$ & $11.69 \pm 5.14$ & $7.14 \pm 3.31$ & $7.54 \pm 2.31$ & 0.01 \\
\hline FDS & $5.65 \pm 3.52$ & $10.12 \pm 7.79$ & $6.06 \pm 4.18$ & $6.65 \pm 5.58$ & 0.14 \\
\hline $\mathrm{FPL}$ & $16.09 \pm 8.08$ & $19.34 \pm 9.97$ & $14.93 \pm 8.89$ & $15.09 \pm 7.71$ & 0.06 \\
\hline$P Q$ & $7.39 \pm 3.36$ & $8.87 \pm 2.21$ & $7.79 \pm 3.32$ & $8.21 \pm 4.91$ & 0.64 \\
\hline
\end{tabular}

*One-way ANOVA

Iranian Rehabilitation Journal

cles involved in working with different types of computer mouse; thus, consistent with the previous studies [12-14], the achieved results supported this fact.

The electrical activity of FPL muscle was the lowest, which can be due to the improvement of hand posture while working with the slanted mouse [15-17]. According to Chen et al., who examined mice with different slopes, the proximity of hand posture to natural mode would reduce the electrical activity of hand muscles [18]. The wrist condition was normal in this study while working with the slanted mouse. Moreover, ulna and radius bones had a lower deviation, compared to using other mice, reducing the electrical activity of the muscles while working with the slanted mouse.

Muller et al. argued that the users' habit of working with new and alternative mice can significantly affect muscle load and muscle electrical activity. They concluded that 5 days of work with the new instrument revealed a significant difference in the electrical activity of muscles, as well as functional parameters such as speed and error $[13,19-21]$. Therefore, the adaptation of users with the slanted mouse can further decrease the electrical activity level of muscles, compared with other mice.

We also compared the effects of slanted mouse and trackball mouse on EDC, ECU, ECR, and FPL muscles. It was determined that the electrical activity reduces in these muscles while working with the slanted mouse, which was superior to the trackball mouse. The form, shape, and holding position of a slanted mouse create the closest hand posture to the natural mode. Therefore, these factors have led to a decrease in the electrical activity of muscles, compared with a trackball mouse.
Comparing the effects of slanted mouse and trackpad mouse on EDC, FDS, ECR, and FPL muscles determined that the electrical activity decreases in these muscles when working with the slanted mouse. Lee et al. compared the newly designed trackpad, standard, and ergonomic mice. They concluded that the hand posture in using a trackpad mouse generated a greater distortion in the wrist, compared to the natural mode [12, 22, 23]. Therefore, the difference in the electrical activity level of EDC, ECR, FDS, and FPL muscles between the trackpad and slanted mice could be attributed to the differences in the posture and hand movements.

The EMG results suggested that a slanted mouse is superior to other mice. Furthermore, the electrical activity of these muscles is reduced when working with this mouse (except for ECU electrical activity that is the lowest with a standard mouse). The slanted mouse may lead the market, compared with other conventional mice.

Further accustom of the users with new ergonomic mice may improve the functional parameters [13]. In addition, the electrical activity of muscles decreases when working with new mice. In the long-term, it can reduce the incidence of musculoskeletal disorders in the wrists and hands of users.

\section{Conclusion}

The results of recording and analyzing EMG in the studied mice suggested that the activity level of EDC, ECR, and FPL muscles was lower, while using a slanted mouse, compared to other types. Being accustomed to a new slanted mouse may decrease the electrical activity of muscles while working with this ergonomic device. This can enhance the 
convenience of working with a mouse. It may also lead to the prevention of musculoskeletal disorders in the wrists and hands of users in the long run.

\section{Ethical Considerations}

\section{Compliance with ethical guidelines}

The Research Council of the Iran University of Medical Sciences in agreement with the Declaration of Helsinki approved all the study procedures prior to the onset of study.

Funding

This work was supported by Iran University of Medical Sciences (Grant No.: 95-01-123-2571).

\section{Authors' contributions}

Study concept and design: Yasser Labbafinejad, Naser Dehghan; Data collection: Mansour Eslami-Farsani; Interpretation of data: Saber Mohammadi, Mohamad Sadegh Ghasemi; Supervision: Mahnoush Reiszadeh; and Writing-review and editing: Naser Dehghan.

\section{Conflict of interest}

The authors declared no conflict of interest.

\section{References}

[1] Khandan M, Koohpaei A, Kohansal Aghchay M, Ebrahimi M H, Khammar A, Arsang Jang S, et al. Assessing the factors predicting work-related musculoskeletal disorders among Iranian Port's Personnel Using Regression Model. Iranian Rehabilitation Journal. 2017; 15(4):309-16. [DOI:10.29252/NRIP. IRJ.15.4.309]

[2] Khandan M, Vosoughi S, Poursadeghiyan M, Azizi F, Ahounbar E, Koohpaei A. Ergonomic assessment of posture risk factors among iranian workers: An alternative to conventional methods. Iranian Rehabilitation Journal. 2018, 16(1):1116. [DOI:10.29252/NRIP.IRJ.16.1.11]

[3] Clancy EA, Morin EL, Merletti R. Sampling, noise-reduction and amplitude estimation issues in surface electromyography. Journal of Electromyography and Kinesiology. 2002 12(1):1-16. [DOI:10.1016/s1050-6411(01)00033-5]

[4] Barreto AB, Scargle SD, Adjouadi M. A practical EMG-based human-computer interface for users with motor disabilities. Journal of Rehabilitation Research and Development. 2000; 37(1):53-64. [PMID]

[5] Lee DL, Fleisher J, McLoone HE, Kotani K, Dennerlein JT. Alternative computer mouse design and testing to reduce finger ex- tensor muscle activity during mouse use. Human Factors. 2007 49(4):573-84. [DOI:10.1518/001872007x215665] [PMID]

[6] Dennerlein JT, Johnson PW. Changes in upper extremity biomechanics across different mouse positions in a computer workstation. Ergonomics. 2006; 49(14):1456-69. [DOI:10.1080/00140130600811620] [PMID]

[7] Hengel KMO, Houwink A, Odell D, van Dieën JH, Dennerlein JT. Smaller external notebook mice have different effects on posture and muscle activity. Clinical Biomechanics. 2008; 23(6):727-34. [DOI:10.1016/j.clinbiomech.2008.01.013] [PMID]

[8] Gray H. Anatomy of the human body. Philadelphia: Lea \& Febiger; 1918.

[9] Buchanan TS, Moniz MJ, Dewald JP, Rymer WZ. Estimation of muscle forces about the wrist joint during isometric tasks using an EMG coefficient method. Journal of Biomechanics. 1993; 26(4):547-60. [DOI:10.1016/0021-9290(93)90016-8]

[10] Konrad P. The ABC of EMG: A practical introduction to kinesiological electromyography. New York: Noraxon; 2005; 1:29-33.

[11] Kumar R, Kumar S. A comparison of muscular activity involved in the use of two different types of computer mouse. International Journal of Occupational Safety and Ergonomics. 2008; 14(3):305-11. [DOI:10.1080/10803548.2008.11076770] [PMID]

[12] Lee YH, Su MC. Design and validation of a desk-free and posture-independent input device. Applied Ergonomics. 2008; 39(3):399-406. [DOI:10.1016/j.apergo.2005.04.006] [PMID]

[13] Müller C, Tomatis L, Läubli T. Muscular load and performance compared between a pen and a computer mouse as input devices. International Journal of Industrial Ergonomics. 2010; 40(6):607-17. [DOI:10.1016/j.ergon.2010.08.004]

[14] Laursen B, Jensen BR, Garde AH, Jorgensen AH. Effect of mental and physical demands on muscular activity during the use of a computer mouse and a keyboard. Scandinavian Journal of Work, Environment \& Health. 2002; 28(4):215-21. [DOI:10.5271/sjweh.668]

[15] Domkin D, Forsman M, Richter HO. Effect of ciliary-muscle contraction force on trapezius muscle activity during computer mouse work. European Journal of Applied Physiology. 2019; 119(2):389-97. [DOI:10.1016/j.jelekin.2015.11.008] [PMID]

[16] St-Onge N, Samani A, Madeleine P. Integration of active pauses and pattern of muscular activity during computer work. Ergonomics. 2017; 60(9):1228-39. [DOI:10.1080/001401 39.2017.1303086] [PMID]

[17] Lin MY, Young JG, Dennerlein JT. Evaluating the effect of four different pointing device designs on upper extremity posture and muscle activity during mousing tasks. Applied Ergonomics. 2015; 47:259-64. [DOI:10.1016/j.apergo.2014.10.003] [PMID]

[18] Chen HM, Leung CT. The effect on forearm and shoulder muscle activity in using different slanted computer mice. Clinical Biomechanics. 2007; 22(5):518-23. [DOI:10.1016/j.clinbiomech.2007.01.006] [PMID]

[19] Dehghan N, Choobineh A, Razeghi M, Hasanzadeh J, Irandoost $\mathrm{M}$. Designing a new computer mouse and evaluating some of its functional parameters. Journal of Research in Health Sciences. 2013; 14(2):132-5. 
[20] Dehghan N, Choobineh A, Razeghi M, Hasanzadeh J, Irandoost $\mathrm{M}$, Ebrahimi S. Assessment of functional parameters and comfort of a new computer mouse as compared with other types of input devices. International Journal of Occupational Safety and Ergonomics. 2015; 21(4):493-7. [DOI:10.1080 /10803548.2015.1096060] [PMID]

[21] Ghasemi MS, Hosseinzadeh P, Zamani F, Ahmadpoor H, Dehghan N. Ergonomic design and evaluation of a diagnostic ultrasound transducer holder. International Journal of Occupational Safety and Ergonomics. 2017; 23(4):519-23. [DOI:10.1 080/10803548.2016.1216763] [PMID]

[22] Labbafinejad Y, Ghasemi MS, Bagherzadeh A, Aazami H, Eslami-Farsani M, Dehghan N. Saddle seat reduces musculoskeletal discomfort in microsurgery surgeons. International Journal of Occupational Safety and Ergonomics. 2017:1-6. [D OI:10.1080/10803548.2017.1389463] [PMID]

[23] Azadi F, Amjad RN, Marioryad H, Alimohammadi M, Karimpour Vazifehkhorani A, Poursadeghiyan M. [Effect of 12-week neck, core, and combined stabilization exercises on the pain and disability of elderly patients with chronic non-specific neck pain: a clinical trial (Persian)]. Iranian Journal of Ageing. 2019; 13(5):614-625. [DOI:10.32598/SIJA.13.Special-Issue.614] 
This Page Intentionally Left Blank 